\title{
ANALYSIS OF FATIGUE CRACKS OF CYLINDER HEADS IN DIESEL ENGINES
}

\author{
HojJat Ashouri, Babak Beheshti \\ Department of Agricultural Machinery, Science and Research Branch, Islamic Azad University, Tehran, Iran \\ e-mail: ashori@samav-ac.ir; Beheshti-b@srbiau.ac.ir \\ Mohammad Reza EBRAhimzadeH \\ College of Agriculture, Yadegar-e-Imam Khomeini (Rah), Shahr-e-rey Branch, Islamic Azad University, Tehran, Iran \\ e-mail: mrebrahimzadeh@iausr.ac.ir
}

\begin{abstract}
Loading conditions and complex geometry have led cylinder heads to become the most challenging parts of diesel engines. One of the most important durability problems in diesel engines is due to cracks in the valves bridge area. The purpose of this study is thermo-mechanical analysis of cylinder heads of diesel engines using a two-layer viscoplasticity model. The results of the thermo-mechanical analysis indicate that the maximum temperature and stress occurr in the valves bridge. The results of the finite element analysis correspond with the experimental tests carried out by researchers, and illustrate cracks in cylinder heads in this region. The results of the thermo-mechanical analysis show that when the engine is running, the stress in the region is compressive, caused by thermal loading and combustion pressure. When the engine is shut off, the compressive stress turns into tensile stress because of assembly loads. The valves bridge is under cyclic tensile and compressive stress state and thus is subject to low cycle fatigue. After several cycles fatigue cracks will appear in this region. The lifetime of this part can be determined through finite element analysis instead of experimental tests. The viscous strain is greater than the plastic strain which is not negligible.
\end{abstract}

Keywords: thermo-mechanical fatigue, finite element analysis, cylinder head and valve bridge cracks

\section{Introduction}

Cylinder heads are important parts of internal combustion engines which are subject to high thermo-mechanical stresses for because the sake of their working environment (Azadi et al., 2012a; Gocmez and Pishinger, 2011; Li et al., 2013 ; Metzeger et al., 2014; Su et al., 2002; Thalmair et al., 2006; Trampert et al., 2008; Zahedi and Azadi, 2012; Xuyang et al., 2013). Therefore, selection of materials is of paramount importance since they must have sufficient mechanical strength at high temperatures to be able to withstand cyclic stresses caused by heat and pressure (Gocmez and Pishinger, 2011; Zahedi and Azadi, 2012; Takahashi and Sasaki, 2010).

High output capacity, low fuel consumption, low emission and reduction costs of maintenance are among the restrictions making the design of cylinder heads a complicated task (Mirsalim et al., 2009; Li et al., 2013). Thus, detailed analysis and design are essential. Escalation in environmental concerns and fuel costs underlines the need for research on more efficient engines with less energy dissipation and emission (Azadi et al., 2012b; Mirsalim et al., 2009). One way to decrease the fuel costs is to reduce weight of vehicles. Hence, lighter alloys must be used in the pursuit of this goal (Azadi et al., 2012a; Zahedi and Azadi, 2012). Recently, the use of aluminum alloys has increased for economic reasons and for the improvement of engine power by 
weight reduction. Aluminum-silicon is a casting alloy which has extensive use in the automotive industry, especially in cylinder heads of diesel engines. These materials have been replaced by a variety of cast iron which were previously used in the manufacture of cylinder heads (Azadi et al., 2012a). Thermal deformation is the greatest challenge faced by aluminum cylinder heads (Takahash et al., 2002).

Cylinder heads are exposed to thermal and mechanical loads. The temperature difference, which is a result of turning the engine on and off, begets thermo-mechanical fatigue (TMF) loads on the cylinder heads (Azadi et al., 2012a; Li et al., 2013; Mirsalim et al., 2009; Farrahi et al., 2014; Thomas et al., 2002; Thomas et al., 2004) and, consequently, reduces their lifetime, especially in thinner regions (Remy and Petit, 2001). The crucial regions include the valves bridge and areas near spark plugs and injectors (Gocmez and Pishinger, 2011; Shojaefard et al., 2006; Ziehler et al., 2005). Cylinder heads endure out-of-phase TMF. Namely, the maximum stress occurs at the minimum temperature and the minimum stress occurs at the maximum temperature. When the engine shuts off and the temperature is low, the tensile stresses arising from the assembly loads will be applied to the cylinder heads. As the engine starts and temperature increases, the compressive stresses produced by thermal loading $\left(\sigma_{t h}\right)$ and combustion pressure $\left(\sigma_{p}\right)$ will be applied to them (Azadi et al., 2012b; Li et al., 2013). This type of loading is displayed in Fig. 1. As the figure reveals, the changes in stress caused by thermal load are very high. The fluctuating stresses come out of the engine which is heated and cooled (Mirsalim et al., 2009; Challen and Baranescu, 1999; Chamani et al., 2009).

Plastic deformation is observed in structures like cylinder heads which bear high temperature fluctuations and assembly loads. Classical models are used to obtain steady responses of these structures. This approach is very expensive. Because many loading cycles are required to obtain a steady response. Cyclic analysis is used in order to avoid the cost of transient analysis (Zahedi and Azadi, 2012).

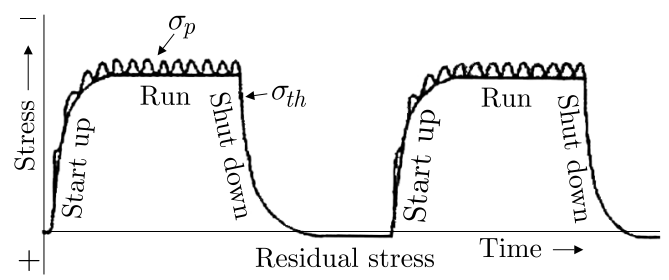

Fig. 1. The cyclic loading of a cylinder head (Challen and Baranescu, 1999)

Numerous papers have been presented on the analysis of stress and fatigue in cylinder heads. Koch et al. (1999) measured experimentally strain of cylinder heads and compared it with simulated results using a nonlinear isotropic/kinematic hardening model. A slight difference between the experimental and simulated strain was observed from $55^{\circ} \mathrm{C}$ to $120^{\circ} \mathrm{C}$. The simulated strain, by increasing temperature from $110^{\circ} \mathrm{C}$ to $210^{\circ} \mathrm{C}$ was estimated larger than the experimental strain due to plastic deformation of the cylinder heads.

Takahashi et al. (2002) examined creep in aluminum cylinder heads. There was concordance between experimental and calculated strain. Creep strain increased as stress grew. Creep strain at $250^{\circ} \mathrm{C}$ significantly was higher than creep strain at $100^{\circ} \mathrm{C}$ and $175^{\circ} \mathrm{C}$.

TMF of cylinder heads was studied by Thomas et al. $(2002,2004)$ using the energy model and elasto-viscoplastic law. Their research proved a good agreement between experimental and simulated results of the fatigue life of the cylinder heads and the location of crack initiation.

Thermo-mechanical analysis of cylinder heads and cylinders of AFV diesel engines was conducted by Venkateswaran et al. (2011). Their research demonstrates that the cylinder heads and engine blocks can tolerate more stress caused by pressure and thermal loads increase, and the next generation of engines does not need further alteration. 
Su et al. (2002) predicted fatigue life of cylinder heads by finite element simulation via the model of damage total (Sehitoglu damage model) and compared with experimental results. Their research revealed that the difference between experimental and simulated results was less than $30 \%$.

Zieher et al. (2005) simulated the complete process of lifetime. They used an energy model to predict the fatigue life of cast iron cylinder heads. Their research shows that the simulated results of the number of cycles of crack initiation and the location of crack initiation are in accord once with experimental results. The minimum lifetime was observed in the valves bridge.

The analysis of high/low cycle fatigue of cylinder heads was performed by Ghasemi (2012) using the thermo-mechanical analysis. His study verified that the cracks observed in the experimental test of low-cycle of cylinder heads acknowledged the simulated results of low-cycle fatigue. The simulated results of low-cycle fatigue of cylinder heads after modification of cooling systems indicate that high levels of damage parameters are do not observed.

Shoja'efard et al. (2006) experimentally measured stress in cylinder heads and compared it with simulated results. Their research confirmed the concordance between the experimental and simulated results at low temperature. The simulated stress at temperatures exceeding $200^{\circ} \mathrm{C}$ was estimated to be greater than the experimental stress due to inelastic material deformation.

Prediction of the fatigue life of cylinder heads of two-stroke linear engines was done by Rahman et al. (2008) using finite element analysis (FEA) and the stress-life approach. Their research refuted the possibility of failure in all spots. Compressive mean stress increases the fatigue life and tensile mean stress lessens the fatigue life.

Gocmez and Pischinger (2011) investigated sophisticated interaction effects of thermal and mechanical loads, geometry of cylinder heads and TMF behavior of the cylinder heads material. They optimized the valves bridge based on the ratio of mechanical to thermal strain. Their research indicates that the vertical temperature gradients are mainly determined by the thickness of the valves bridge which plays a role in the distribution of temperature. Geometric dimensions of the valves bridge and thermal conductivity were the most outstanding parameters in the thermo-mechanical analysis of the cylinder heads.

Thalmair et al. (2006) established the TMF/computer aided engineering (CAE) process for fatigue assessment of cylinder heads. Their research proved an acceptable agreement between experimental and simulated results of the fatigue life of the cylinder heads. They predicted the locations of fatigue cracks in the cylinder heads accurately.

Mirslim et al. (2009) calculated low cycle fatigue life by finite element simulation of cylinder heads based on various criteria of the strain state. Their experiments show that by cutting the valves bridge, one can increase the fatigue life of cylinder heads.

Trampert et al. (2008) studied the effects of thermo-mechanical loads on cylinder heads. Their research indicated concordance between experimental and simulated results of the fatigue life of the cylinder heads. Crucial locations in the analysis of fatigue were the same locations of crack initiation in the experimental conditions. There was conformity between the number of cycles of calculated failure and the experimental results of macroscopic observation of cracks.

Zahedi and Azadi (2012) compared the stress and low-cycle fatigue life of aluminum and magnesium cylinder heads of diesel engines. Their research showed that the strain in magnesium cylinder heads was greater in comparison with the aluminum ones, while the magnesium cylinder heads had less stress. The fatigue life of the both cylinder heads was almost identical.

Azadi et al. (2012a) analyzed cracked cylinder heads of gasoline engines. Examining materials and doing finite element analysis of the cracked cylinder heads stress, they determined the cause of cracks and provided some solutions. Their research revealed that the main reason for cracks initiation in cylinder heads was high stress and plastic strain caused by assembly loads of the cylinder heads bolts. 
TMF analysis of gray cast iron cylinder heads was conducted by Li et al. (2013). An acceptable agreement between experimental and simulated results of TMF life was proved. Improving and optimizing the structure of cylinder heads doubled their fatigue life.

Xuyang et al. (2013) predicted TMF life of diesel engines cylinder heads. Their research revealed that the discrepancy between experimental and simulated results was $3 \%$. The energy criterion accurately predicted fatigue life in the valves bridge compared with thermal shock tests.

Metzger et al. (2014) predicted the lifetime of cast iron cylinder heads under thermo-mechanical loads and high-cycle fatigue. According to their study, the experimental and simulated results of temperature matched. The mechanical analysis correctly anticipated the position and direction of cracks in the valves bridge. Comparing with experimental results, the anticipation of fatigue life was rather conservative.

Aluminum cylinder heads must be adequately robust to tolerate gas pressure, assembly loads and high temperature resulting from ignition to avoid cracking the valves bridge (Takahashi et al., 2010). Thermo-mechanical loading cylinder heads can only be controlled through modern cooling systems or protective coatings such as thermal barrier coating (TBC) reducing heat stress and thereby reducing the temperature gradient (Bialas, 2008).

Azadi and colleagues studied the impact of TBC on cylinder heads. The results of their research demonstrated the TBC reduced the temperature gradient and, consequently, the thermal stress. Hence fatigue life of cylinder heads was augmented (Azadi et al., 2013; Moridi et al., 2011a, 2011b; Moridi et al., 2014).

According to the introduction, due to lack of information on the behavior of hardening, softening and viscosity of materials, the analysis of cylinder heads is mostly based on simple models of material behavior like elastic-plastic, and the effects of viscosity and creep of cylinder heads are less taken into consideration. Aluminum alloy has creep behavior at about $300^{\circ} \mathrm{C}$ and viscosity should also be taken into account ( $\mathrm{Su}$ et al., 2002; Thomas et al., 2002, 2004; Koch et al., 1999). The main objective of this study is to simulate thermo-mechanical behavior of cylinder heads based on the two-layer viscoplasticity model. In some analyses, it is assumed that temperature changes have no effect on the stress-strain curves, and the thermo-mechanical analysis of cylinder heads is non-coupled. Since changes in temperature influence the stress-strain curves, the thermo-mechanical analysis of cylinder heads in this study is coupled.

\section{The material and its behavioral model}

In this study, the cast alloy of aluminum-silicon-magnesium has been used to simulate the thermo-mechanical behavior. The alloy is known as A356.0 or AlSi7Mg0.3 which is applied in diesel engines cylinder heads (Farrahi et al., 2014; Moridi et al., 2011a, 2011b, 2014). The chemical composition of A356.0 is 7.06 wt. \% Si, 0.37 wt. \% Mg, 0.15 wt. \% Fe, 0.01 wt. \% Cu, 0.02 wt. \% Mn, 0.13 wt. \% Ti, and Al remainder (Farrahi et al., 2014).

The two-layer viscoplasticity model divides the elastic and viscosity effects into two elasticviscous and elastic-plastic networks. As displayed in Fig. 2, this model was presented by Kichenin et al. (1996). This model makes the cyclic stress-strain behavior of the material predictable with reasonable accuracy (Deshpande et al., 2010).

This model consists of a network of elastic-plastic elements parallel to a network of elastic-viscous ones. Plastic deformation and creep can be seen in structures such as cylinder heads which are under assembly loads and temperature fluctuations. The two-layer viscoplasticity model is the best to examine the response of materials such as aluminum which remarkably dependent behavior on temperature and is plastic at high temperatures (Metzeger et al., 2014; Farrahi et al., 2014; Zahedi and Azadi, 2012; Deshpande et al., 2010; Thalmair et al., 2006). 


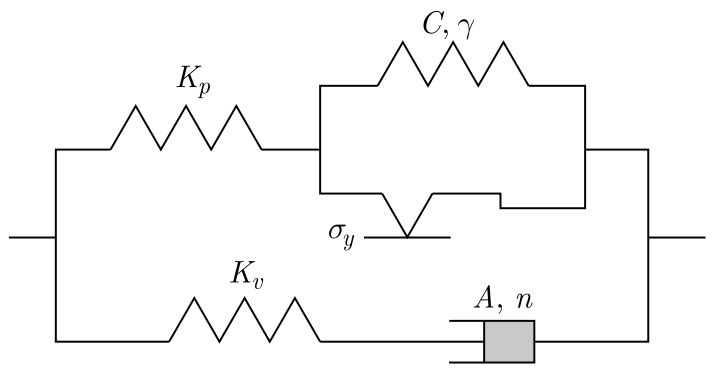

Fig. 2. The two-layer viscoplasticity model (Deshpande et al., 2010)

This model is in good agreement with the results of experimental and thermo-mechanical tests on A356.0 alloy (Farrahi et al., 2014).

The material behavior of different aluminum-silicon casting alloys was described by the nonlinear kinematic/isotropic hardening model in Abaqus software (Koch et al., 1999).

In the plastic network, a nonlinear kinematic/isotropic hardening model is applied which predicts the behavior such as hardening, softening, creep and mean stress relaxation, and it is a suitable model for the plastic behavior of materials (Farrahi et al., 2014; Deshpande et al., 2010).

Kinematic hardening has both linear and nonlinear isotropic/kinematic models. The first model can be used with the Mises or Hill yield surface while the second one can only be used with the Mises yield surface, and it is the most accurate and comprehensive model to examine some issues with cyclic loading including cylinder heads of engines. The kinematic hardening model assumes that the the yield surface, proportional to the value of $\alpha$, moves as the back stress in yield zone but it does not deform (Lemaitre and Chaboche, 1990). Abaqus software uses the Ziegler linear model (Lemaitre and Chaboche, 1990). To simulate this model, the following equation is given:

$$
\dot{\sigma}=C \frac{1}{\sigma^{0}}\left(\sigma_{i j}-\alpha_{i j}\right) \dot{\bar{\varepsilon}}^{P L}+\frac{1}{C} \dot{C} \alpha_{i j}
$$

where $C$ is the kinematic hardening modulus, $\dot{C}$ is the exchange rate of $C$ in temperature and $\dot{\bar{\varepsilon}}^{P L}$ is the rate of equivalent plastic strain. In this model, $\sigma^{0}$ (size of the yield surface) remains constant. In other words, $\sigma^{0}$ is always equal to $\sigma_{0}$ (that is the yield stress in zero plastic strain) and remains constant. The nonlinear isotropic/kinematic hardening model includes motion of the yield surface proportional to the value of $\alpha$ in the stress zone, and also the changes in size of the yield surface are proportional to the plastic strain (Lemaitre and Chaboche, 1990). This model has been extracted from the Chaboche experience (Chaboche, 1986, 2008). In order to introduce this model a nonlinear term is added to equation (2.1) to indicate size of the yield surface (Lemaitre and Chaboche, 1990).

Abaqus software uses the nonlinear isotropic/kinematic hardening model given by the following equation:

$$
\dot{\alpha}=C \frac{1}{\sigma^{0}}\left(\sigma_{i j}-\alpha_{i j}\right) \dot{\bar{\varepsilon}}^{P L}-\gamma_{i j} \dot{\bar{\varepsilon}}^{P L}+\frac{1}{C} \dot{C} \alpha_{i j}
$$

where $C$ and $\gamma$ are material constants. In order to introduce this model in to Abaqus software the isotropic and the kinematics parts are required to be defined separately (Farrahi et al., 2014). In order to define the isotropic part, equation (2.3) is used in which $b$ and $Q_{\infty}$ are material constants (Deshpande et al., 2010).

$$
\sigma^{0}=\sigma_{0}+Q_{\infty}\left(1-\exp \left(b \dot{\bar{\varepsilon}}^{P L}\right)\right)
$$


The overall back stress is computed from relation (2.4) (Lemaitre and Chaboche, 1990):

$$
\alpha=\sum_{K=1}^{N} \alpha_{K}
$$

In equation (2.4), if we consider $N$ equal to 3 , the hardening variable is divided into three parts, which increases the accuracy of the model (Farrahi et al., 2014).

The Norton-Hoff law is used for the viscous network in order to consider the effect of strain rate the equation of which is the following (Angeloni, 2011):

$$
\dot{\varepsilon}_{V}=A\left(\sigma_{V}\right)^{n}
$$

where the $\dot{\varepsilon}_{V}$ is viscous strain rate, $A$ and $n$ are material constants and $\sigma_{V}$ is the viscous stress.

According to equation (2.6), the rate of the elastic modules in the two viscous and plastic networks is express by $f$, where $k_{v}$ and $k_{p}$ are elastic moduli in the elastic-viscous and elastic-plastic networks, respectively (Deshpande et al., 2010)

$$
f=\frac{k_{v}}{k_{v}+k_{p}}
$$

\section{The finite element model and material properties}

Traditionally, optimization of engine components such as cylinder is was based on building a series of physical prototypes, and performing a series of different experiments and tests. Unfortunately, this method is time consuming, and building a prototype at the early stages of the design is arduous. Many samples must be constructed and tested in order to achieve the precise design. This process is costly. These problems are resolved using finite element analysis to evaluate the effectiveness of various designs. This technique is accepted for the design and development of geometrically complex components such as cylinder heads in a shorter period and with the least cost. Cylinder heads are complex and challenging components of engines, for which the finite element analysis plays a critical role in optimization (Shojaefard et al., 2006). TMF analysis of each component needs the cyclic stress-strain distribution. Hot components of diesel engines have complex geometry and loading, and the application of analytical methods for detection of stress-strain distribution in them is impossible. Many researchers have used the finite element method to obtain stress-strain distributions in of geometrically complex components (Sun and Shang, 2010). Nowadays, simulation techniques are substituted to validation tests so as to decrease the cost and time of production (Trampert et al., 2008).

The cylinder heads examined in this study are shown in Fig. 3.

The cylinder heads have three valve ports, each with an embedded valve seat, two valve guides and four bolt holes used to secure the cylinder head to the engine block. The cylinder heads are made of aluminum alloy (A356.0). The two valve guides are made of steel, with Young's modulus of $106 \mathrm{GPa}$ and Poisson's ratio of 0.35 . The valve guides fit tightly in the two cylinder heads and their behavior is presumed elastic. The three valve seats are made of steel with Young's modulus of $200 \mathrm{GPa}$ and Poisson's ratio of 0.3. The valve seats are press-fit into the cylinder head valve ports. This is accomplished by defining radial constraint equations (ABAQUS User's Manual, 2010).

The model consists of 65580 nodes and approximately 80000 degrees of freedom. The loading of the cylinder heads loading is applied in two phases involving thermal analysis and mechanical analysis.

The values of $f, n, A$ and $Q_{\infty}$ are extracted from the experimental results of A356.0 by Farrahi et al. (2014) and they are entered into the Abaqus software. 


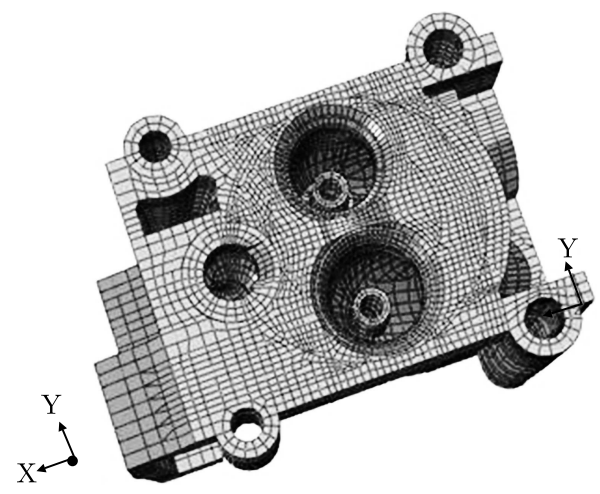

Fig. 3. A meshed cylinder head (ABAQUS/CAE User's Manual, 2010)

There are several methods to insert the values of $C$ and $\gamma$ into Abaqus software. One of them is entering the yield stress at plastic strain using the midlife cycle (Farrahi et al., 2014). The yield stress at plastic strain was extracted from the data by Farrahi et al. (2014) by means of the results of conducted experiments on A356.0 and entered into the Abaqus software.

\section{Results and discussion}

\subsection{Thermal analysis}

Thermal stresses in the cylinder heads are the dominant stresses leading to low cycle fatigue. Low cycle fatigue is caused by repeated start-up and shout-down cycle of the engine (Mirsalim et al., 2009; Thomas et al., 2002, 2004; Ghasemi, 2012).

The main part of the cylinder heads stresses results from thermal loading and the rest is caused by the combustion pressure and mechanical constraints (Fig. 1) see Mirsalim et al. (2009) and Shojaefard et al. (2006). Therefore, thermal loading is the most important loading in the thermo-mechanical analysis. Knowing the precise distribution of temperature, one may increases the accuracy of thermal analysis (Mirsalim et al., 2009). Accurate prediction of temperature of the engine is very crucial and increases the precision of the FEA results (Ghasemi, 2012). As the accuracy of thermal analysis increases, the accuracy of mechanical analysis and fatigue life estimation rises (Thomas et al., 2002, 2004). The combustion pressure causes high cycle fatigue in the cylinder heads (Azadi et al., 2012a; Metzeger et al., 2014). Many researchers believe that the combustion pressure has a secondary effect in the TMF (Takahash et al., 2002; Thomas et al., 2002, 2004). In finite element simulation the valves bridge, where the greatest thermal concentration exists, is subjected to thermal loading ranging from a minimum of $35^{\circ} \mathrm{C}$ to the maximum of $300^{\circ} \mathrm{C}$ (Zahedi and Azadi, 2012). The temperature distribution when the cylinder heads are heated to its peak value is shown in Fig. 4. Thermal loading has a considerable effect on the fatigue life, and the temperature field identifies the critical regions (Trampert et al., 2008). Crack initiation is due to changes in the temperature field (Thalmair et al., 2006).

Plastic deformation and creep are observed under such conditions. The two-layer viscoplastic model is ideally suited to examination of the response of materials in these conditions (Metzeger et al., 2014; Farrahi et al., 2014; Zahedi and Azadi, 2012; Deshpande et al., 2010). The cyclic thermal loads are obtained by performing independent thermal analysis. In this analysis, three thermal cycles are applied to obtain a steady-state thermal cycle. Each thermal cycle involves two steps: heating the cylinder heads to the maximum operating temperature and cooling it down to the minimum operating temperature using *CFLUX and *FILM options. The nodal temperatures for the last two steps (one thermal cycle) are assumed to be a steady-state solution 


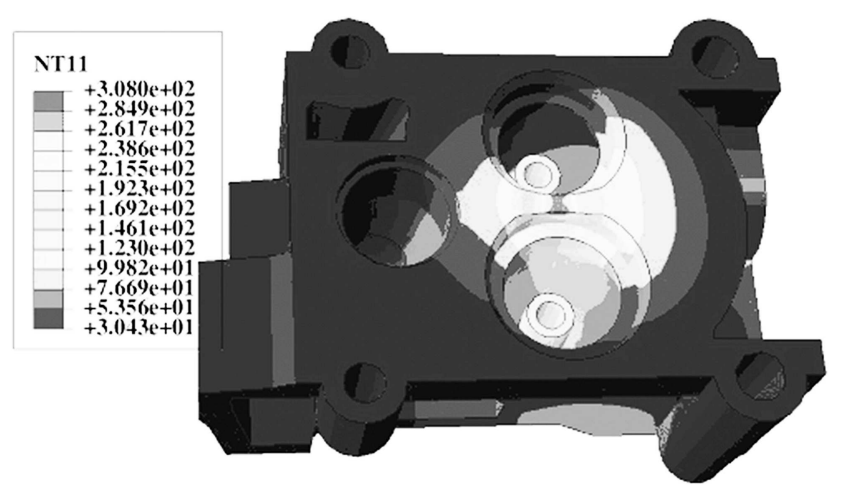

Fig. 4. Temperature distribution in the cylinder head

and the results are stored for use in the subsequent thermao-mechanical analysis (Zahedi and Azadi, 2012). The maximum temperature occurred in the valves bridge.

The temperature in this region (node 50417) is shown in Fig. 5 as a function of time for a steady-state cycle, representing the cycle of turning the engine on and off. The lower is temperature of the flame and the gradient temperature of the parts of cylinder heads, the less is the thermal stress. Thus, low cycle fatigue life, which is mainly affected by thermal fatigue, will increase (Chamani et al., 2009).

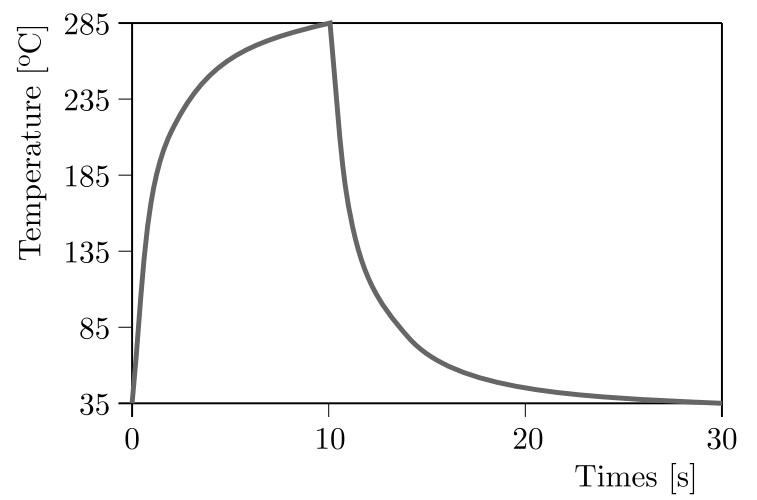

Fig. 5. The temperature at node 50147 versus time

\subsection{Mechanical analysis}

Mechanical analysis has been carried out in two stages. In the first stage, the three valve seats are press-fit into the corresponding cylinder heads valve ports. A static analysis procedure is used for this purpose. The maximum principal stress distribution is depicted in Fig. 6 proving thet the stress in the valves bridge is tensile.

Figure 7 demonstrates the vectors of the maximum principal stress at this stage in the valves bridge. As can be seen, the maximum principal stress in the valves bridge is tensile.

The cyclic thermal loads are applied in the second step of the analysis. It is assumed that the cylinder heads are securely fixed to the engine blocks through the four bolt holes, so the nodes along the base of four bolt holes are secured in all directions during the entire simulation (Zahedi and Azadi, 2012). Von Mises stress distribution at the end of the second stage is shown in Fig. 8. The maximum stress and the maximum temperature occurred in the valves bridge. As shown in Fig. 9, some regions of the cylinder heads entered into yield zone. As mentioned by Azadi et al. (2012a), Metzeger et al. (2014), Takahashi et al. (2002), Shojaefard et al. (2006), these regions are where the fatigue cracks initiate. These regions are also located in the valves bridge. 


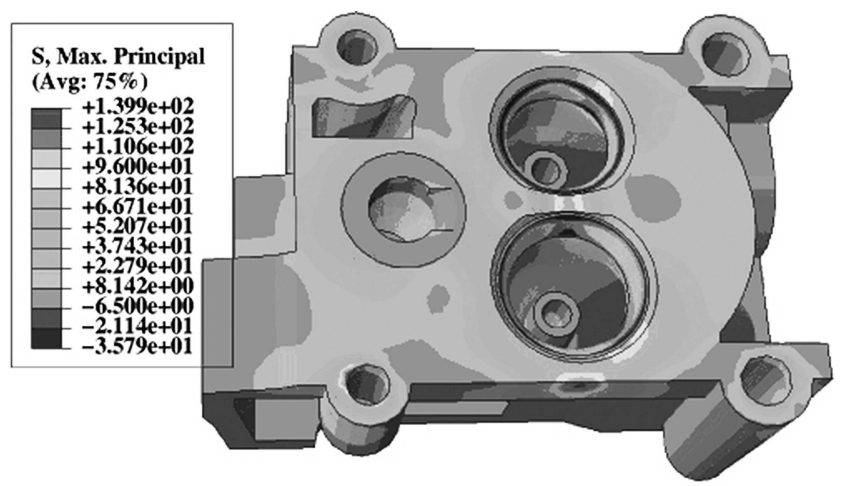

Fig. 6. The maximum principal stress distribution in the first stage of mechanical loading

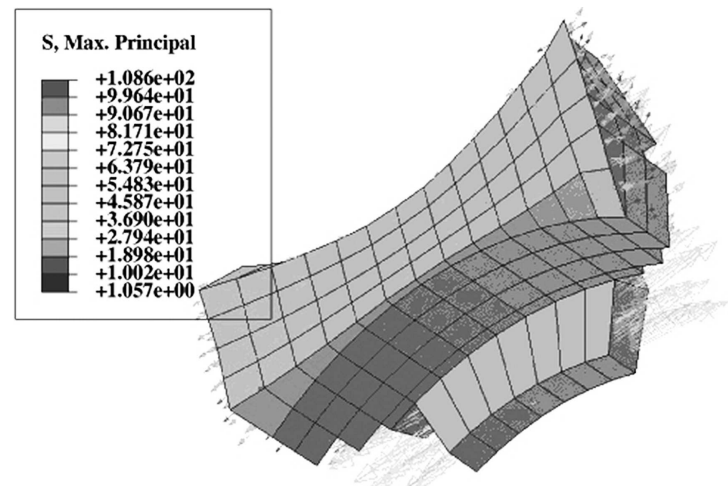

Fig. 7. The maximum principal stress vectors in the valve bridges due to assembly loads

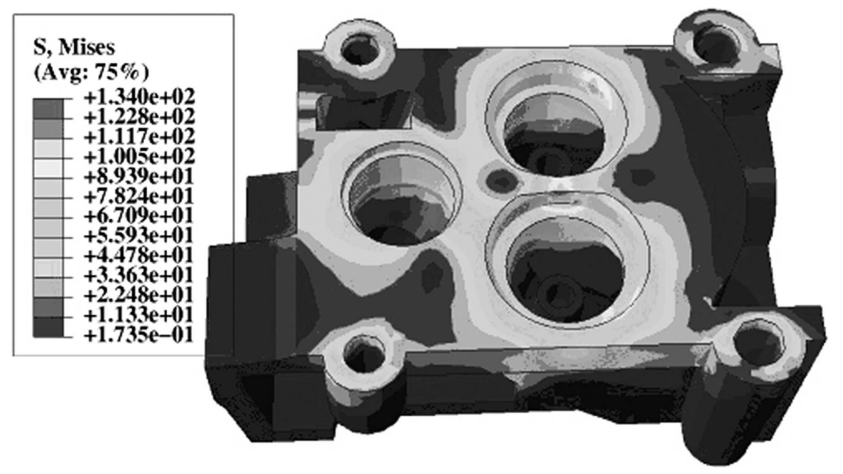

Fig. 8. Von Mises stress distribution at the end of the second stage of mechanical loading

Based on the works by Gocmez and Pishinger (2011) and Ghasemi (2012), the result of loading in the yield surface and ultimate strength is the initiation and propagation of fatigue cracks in less than 10.000 cycles. The equivalent plastic strain distribution is depicted in Fig. 10.

As stated by Li et al. (2013), Koch et al. (1999), the initiation of fatigue cracks in the cylinder heads occurs where the stress is tensile because of the assembly loads, and the plastic strain is due to thermo-mechanical loads. This region is also located in the valves bridge.

Based on the work by Metzeger et al. (2014), the first fatigue cracks can be seen at the hottest spot of the cylinder heads (Fig. 4). The review of Fig. 4, 6-10 reveals that the results of finite element analysis corresponds with the experimental tests. Cracked cylinder heads in the experimental tests are shown in Fig. 11a and 11b. The location of cracks is in the valves bridge. This region endures the maximum stress due to smaller thickness of the material and 


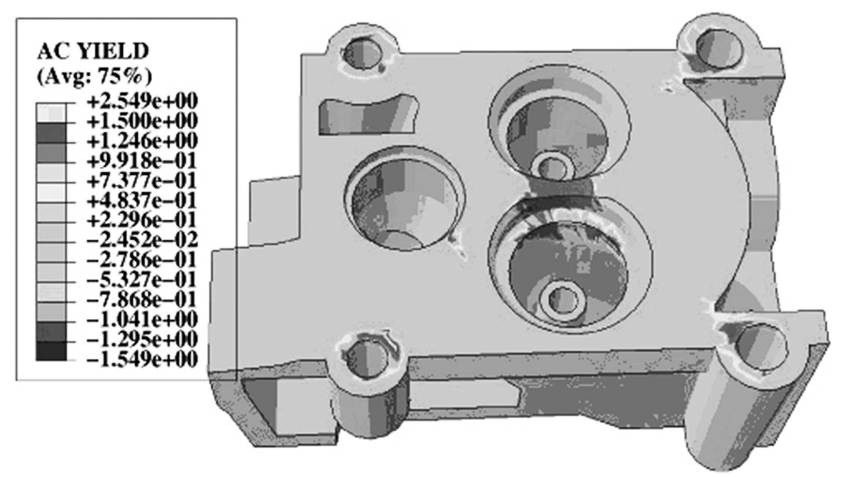

Fig. 9. Regions of the cylinder head entered into the yield zone

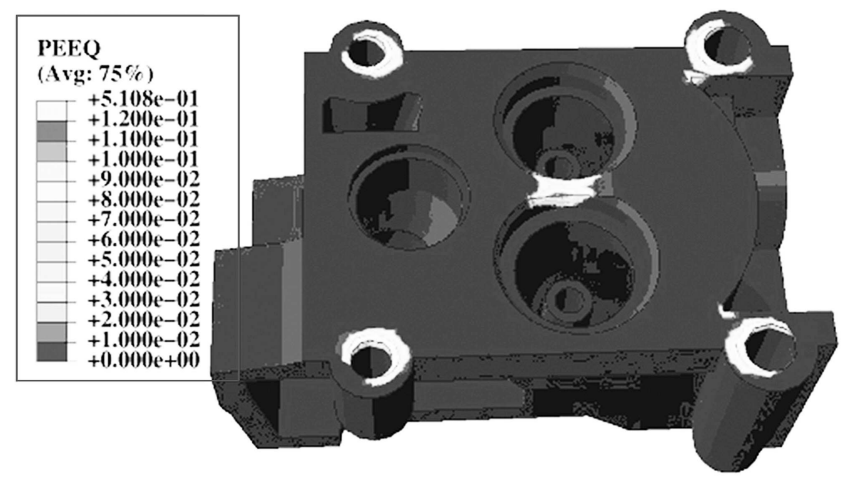

Fig. 10. The equivalent plastic strain distribution

(a)

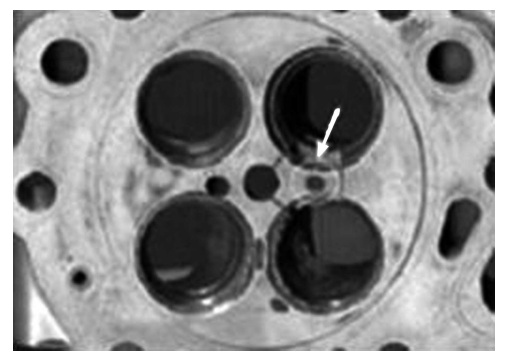

(b)

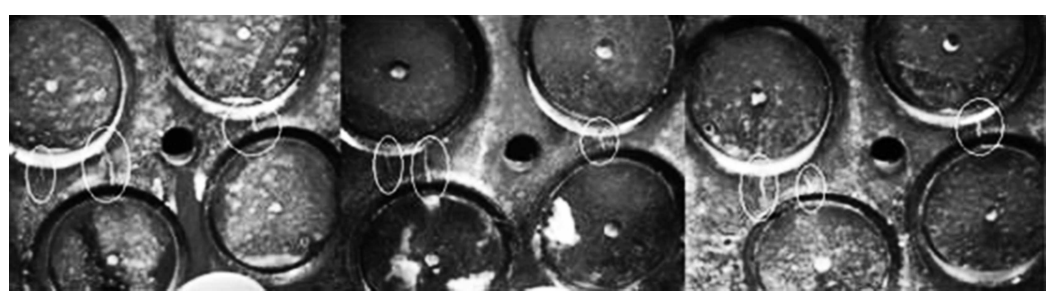

Fig. 11. The cracked diesel engine cylinder head: (a) Takahashi et al. (2010), (b) Li et al. (2013)

high temperature caused by lack of proper cooling. Ergo, the cylinder heads will crack. Stress functions are inverse to the thickness of the material. Namely, the thinnest locations withstand the highest stress. If the valves bridge becomes wider, it will be cooled better and, consequently, the temperature gradient and thermal stress will reduce. Thus, the fatigue life of cylinder heads increases (Gocmez and Pishinger, 2011).

The finite element model predicts a large compressive stress field in the valves bridge as shown in Fig. 8. Thermal expansion of hot spots in the cylinder heads are constrained by cool regions which have less thermal expansion. As a result, compressive stress is created in the valves bridge which corresponds to the results by Shojaefard et al. (2006). Figure 12 displays a diagram of normal stresses (S11), plastic stress (PS11) and viscous stress (VS11) in the $X$ direction for point 1 of element 50152. These elements are in the valves bridge.

The cracking mechanism takes place when the engine is running and warm, reaching the highest temperature. The engine experiences the maximum temperature in the tenth second of operation (Fig. 5). The stresses are compressive because of the thermal loading and combustion pressure at that moment (Fig. 12). Figure 13 demonstrates the vectors of the maximum principal 


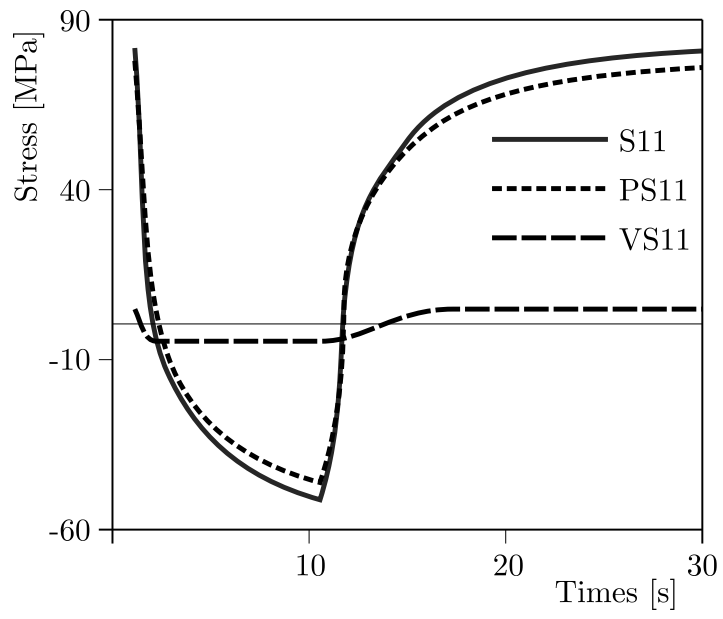

Fig. 12. Normal, plastic and viscous stresses in the $X$ direction for point 1 of element 50152 versus time
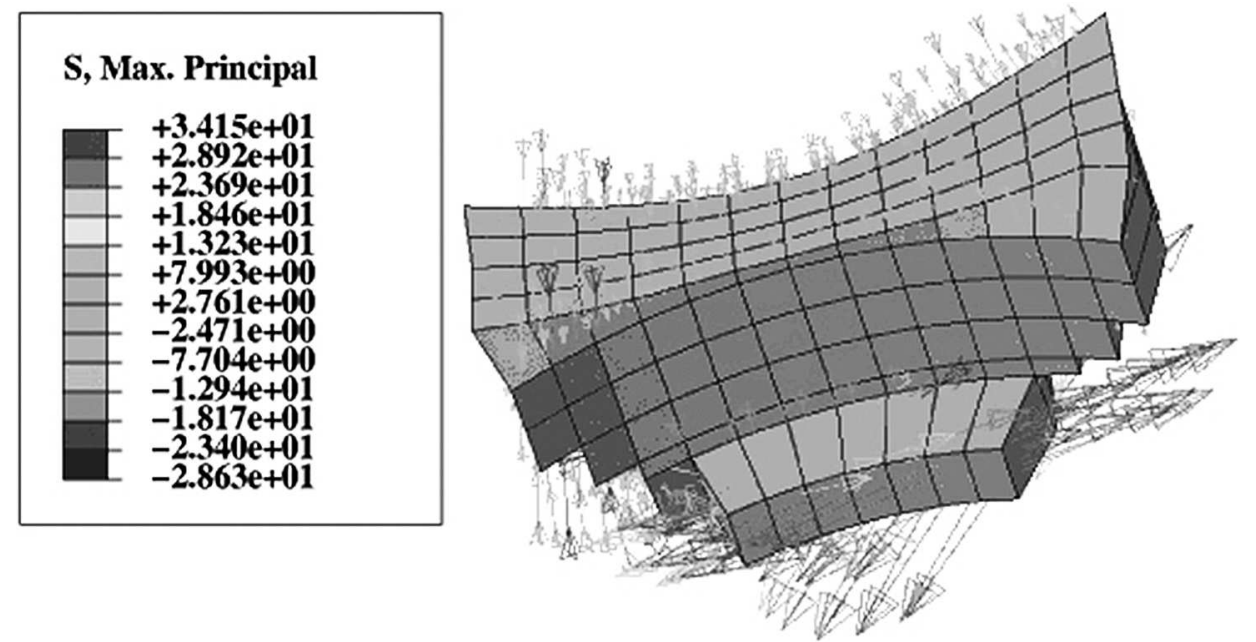

Fig. 13. The maximum principal stress vectors in the valve bridge when the engine is running (in the tenth second)

stress in the valves bridge when the engine is running. As can be seen the maximum principal stress in the valves bridge is compressive. The thermal loading and mechanical constraints generate a compressive stress field, which may lead drive to a compressive yield surface (Fig. 9). As the engine shuts off and its temperature gradually decreases to the room temperature, the stress is tensile due to assembly loads (Fig. 12). Figure 14 shows the vectors of the maximum principal stress in the valves bridge when the engine is shut off. As can be noticed the maximum principal stress in the valves bridge is tensile.

The yielding regions of the cylinder heads cannot return to the primary condition. Hence, tensile stress is created in this area and elastic regions. The stress field for the yield surfaces is compressive at high temperature and turns into tensile stress at low temperature. This corresponds to the results by Li et al. (2013), Takahashi et al. (2002), Koch et al. (1999). The valves bridge is under cyclic tensile and compressive stresses which correspond to the results by Xuyang et al. (2013). According to Takahashi et al. (2002), changes in the cyclic compressive and tensile stresses cause cracks in cylinder heads. As noted by Koch et al. (1999), after a few cycles the aluminum alloy ages and drastically loses its strength. The aged material is unable to resist high tensile stresses, then cracks in the cylinder heads appear. As seen in Fig. 12, the describes viscous stress is low and the normal and plastic stresses are almost identical. Diagrams of the equivalent plastic viscous strains for point 1 of element 50152 are displayed in Fig. 15. 

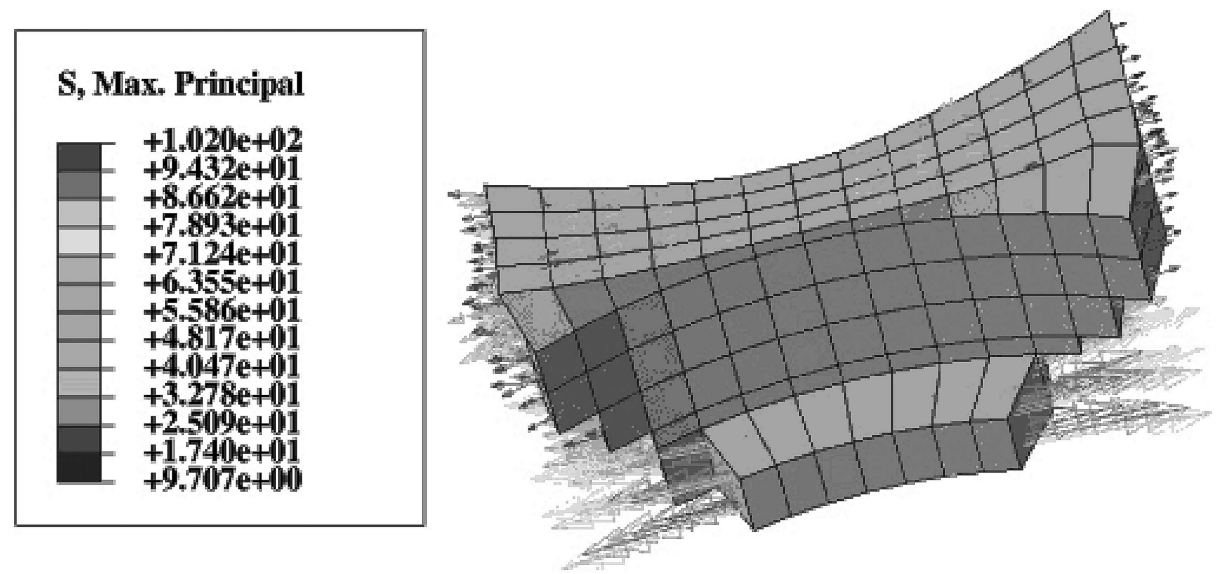

Fig. 14. The maximum principal stress vectors in the valve bridge when the engine shut off (in the thirtieth second)

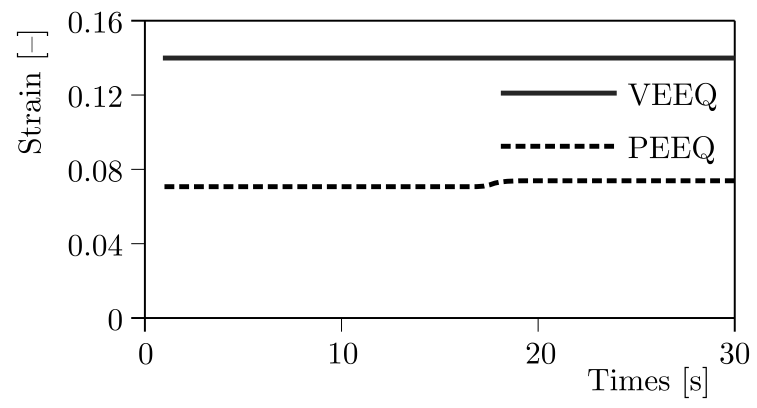

Fig. 15. The equivalent plastic and viscous strain for point 1 of element 50152 versus time

As can be observed, the viscous strain is greater than the plastic strain, and its amount is not negligible. Thus, viscous properties must be considered in the thermo-mechanical analysis of cylinder heads.

\section{Conclusion}

In this paper coupled thermo-mechanical analysis of cylinder heads in diesel engines is studied. A two-layer viscoplasticity model is used for this purpose. This model makes the cyclic stress-strain behavior of the material predictable. Finite element analysis provides an accurate and reliable prediction of temperature and fatigue for design of the cylinder heads. The obtained FEA results show that the stresses inside the combustion chamber exceed the elastic limit. The thermo-mechanical analysis indicats that the maximum temperature and stress occur in the valves bridge. The results of the finite element analysis correspond with the experimental tests carried out by researchers, and illustrate cracks of the cylinder heads in this region. The finite element analysis proves that the stresses in the valves bridge are compressive when the engine is running and become tensile when the engine is shut off. The valves bridge is subjected to cyclic tensile and compressive stress, in which the plastic strain appears. Low-cycle fatigue always occurs in this region and fatigue cracks appear after a few cycles. Changes in the cyclic compressive and tensile stresses cause cracks in the cylinder heads. In order to prevent them from cracking, it is recommended to modify the cooling system of engines as well as thickness and geometry of the material in crucial parts. Since thinner regions endure high stress, cylinder heads crack in these regions. TBC might also be used in the regions which not only boost the engine performance, but also increase the fatigue life of cylinder heads. Since they reduce thermal 
stress, the fatigue life grows. Materials of high thermal conductivity can be used in these regions. Materials of high thermal conductivity decrease the maximum temperature in this region, leading to an increase in the fatigue life of the cylinder heads. Cutting the valves bridge approaches the region to word cooling jackets of cylinder heads. Consequently, the temperature in the region decreases and the fatigue life increases. Thermo-mechanical analysis can determine the optimum cutting to achieve the desired lifetime. It is worth noticing that the amount of the material which is cut is small. However, the increase in volume that is created in the combustion chamber can be compensated by cutting the liner to avoid changes in the engine compression ratio. The viscous strain is greater than the plastic strain, and it is of significant value. Thus, viscous properties must be considered in the thermo-mechanical analysis of cylinder heads. Temperature is effective on stress-strain curves, and the thermo-mechanical analysis of cylinder heads must be coupled.

\section{References}

1. ABAQUS/CAE(v6.10-1), 2010, User's Manual

2. Angeloni M., 2011, Fatigue Life Evaluation of A356 Aluminum Alloy Used for Engine Cylinder Head, Ph.D. Thesis, University of Sao Palo, Brazil

3. Azadi M., Balo M., Farrahi G.H., Mirsalim S.M., 2013, A review of thermal barrier effects on diesel engine performance and components lifetime, International Journal of Automotive Engineering, 3, 305-317

4. Azadi M., Mafi A., Roozban M., Moghaddam F., 2012a, Failure analysis of a cracked gasoline engine cylinder head, Journal of Failure Analysis and Prevention, 12, 286-294

5. Azadi M., Winter G., Farrahi G.H., Eichlseder W., 2012b, Design of cylinder head and block in international combustion engines based on fatigue strength of materials, 8th International Conference on Internal Combustion Engines and Oil, Tehran

6. Bialas M., 2008, Finite element analysis of stress distribution in thermal barrier coating, Journal of Surface and Coating, 202, 6002-6010

7. Снавосне J.L., 1986, Time-independent constitutive theories for cyclic plasticity, International Journal of Plasticity, 2, 2, 149-188

8. Chaвoche J.L., 2008, A review of some plasticity and viscoplasticity constitutive theories, International Journal of Plasticity, 24, 1642-1693

9. Challen B., Baranescu R., 1999, Diesel Engine Reference Book, Butterworth-Heinemann

10. Chamani H.R., Sattarifar I., Mohammadi Aghdam M., 2009, Study of effect combustion gases and cooling thermal boundary conditions on temperature distribution of a heavy diesel engine cylinder head, Journal of Engine Research, 17, 71-81

11. Deshpande A., Leen S.B., Hyde T.H., 2010, Experimental and numerical characterization of the cyclic thermo-mechanical behavior of a high temperature forming tool alloy, ASME Journal of Manufacturing Science and Engineering, 132, 1-12

12. Farrahi G.H., Ghodrati M., Azadi M., Rezvani Rad M., 2014, Stress-strain time-dependent behavior of A356.0 aluminum alloy subject to cyclic thermal and mechanical loading, Mechanics of Time-Dependent Materials, 18, 475-491

13. Ghasemi A., 2012, Cylinder head high/low cycle fatigue CAE analysis, SAE International Paper, No. 2012-01-1999

14. Gocmez T., Pishinger S., 2011, A contribution to the understanding of thermo-mechanical fatigue sensitivities in combustion engine cylinder heads, Journal of Automobile Engineering, 225, $461-477$ 
15. Kichenin J., Dang van K., Boytard K., 1996, Finite-element simulation of a new two-dissipative mechanisms model for bulk medium-density polyethylene, Journal of Material Science, 32, 1653-1661

16. Kосh F., Massan F., Deuster U., Loeprecht M., Marckward H., 1999, Low cycle fatigue of aluminum cylinder heads - calculation and measurement of strain under fired operation, $S A E$ International Paper, No. 1999-01-0645

17. Lemaitre J., Chaboche J., 1990, Mechanics of Solid Materials, Cambridge University Press, Cambridge

18. Li J., Wang P., Cui X., Li K., Yi R., 2013, Gray cast iron cylinder head thermal mechanical fatigue analysis, Proceedings of the FISITA 2012 World Automotive Congress Lecture Notes in Electrical Engineering, 189, 243-257

19. Metzeger M., Leidenfrost M., Werner E., Riedel H., Seifert T., 2014, Lifetime prediction of EN-GJV 450 cast iron cylinder heads under combined thermo-mechanical and high fatigue loading, SAE International Paper, No. 2014-01-9047

20. Mirsalim S.M., Chamani H.R., Rezaloo Y., Keshavarz M., Jafarabadi M., 2009, Analysis of cracked cylinder head of diesel engine due to fatigue and improvement of its design, 6th International Conference on Internal Combustion Engines, Tehran

21. Moridi A., Azadi M., Farrahi G.H., 2011a, Coating thickness and roughness effect on stress distribution of A356.0 under thermo-mechanical loading, Journal of Procedia Engineering, 10, 1372-1378

22. Moridi A., Azadi M., FArrahi G.H., 2011b, Numerical simulation of thermal barrier coating system under thermo-mechanical loading, Word Congress on Engineering, London

23. Moridi A., Azadi M., Farrahi G.H., 2014, Thermo-mechanical stress analysis of thermal barrier coating system considering thickness and roughness effects, Journal of Surface and Coating, 243, 91-99

24. Rahman M.M., Arffin A.K., Abdullah S., Noor M.M., Baker R.A., Maleque M.A., 2008, Fatigue life prediction of cylinder head for two stroke linear engine using stress-life approach, Journal of Applied Science, 8, 3316-3327

25. Remy L., Petit J., 2001, Temperature-Fatigue Interaction, Elsevier

26. Shoja'efard M.H., Ghaffarpour M.R., Nourpour A.R., Alizadenia S., 2006, Thermo-mechanical analysis of an engine cylinder head, Journal of Automotive Engineering, 220, 627-636

27. Su X., Zubeck M., Lasecki J., Engler-Pinto Jr C.C., Tang C., Sehitoglu H., Allison J., 2002, Thermal fatigue analysis of cast aluminum cylinder heads, SAE International Paper, No. 2002-01-0657

28. Sun G.Q., Shang D.G., 2010, Prediction of fatigue lifetime under multiaxial cyclic loading using finite element analysis, Journal of Material and Design, 31, 126-133

29. Takahashi T.I., Nagayoshi T., Kumano M., Sasaki K., 2002, Thermal plastic-elastic creep analysis of engine cylinder head, SAE International Paper, No. 2002-01-585

30. TAKAhashi T.I., SAsAKi K., 2010, Low cycle fatigue of aluminum alloy cylinder head in consideration of changing metrology microstructure, Journal of Procedia Engineering, 2, 767-776

31. Thalmair S., Thiele J., Fishersworring-Bunk A., Ehart R., Guillou M., 2006, Cylinder heads for high power gasoline engines thermo-mechanical fatigue life prediction, SAE International Paper No. 2006-01-0655

32. Thomas J.J., Vergner L., Bignonnet A., Borret S.M., 2002, Thermo-mechanical design in the automotive industry, SAE International Paper, No. 2002-01-0659

33. Thomas J.J., Vergner L., Bignonnet A., Charkaluk E., 2004, Thermo-mechanical design in the automotive industry, Journal of Fatigue and Fracture of Engineering Material and Structure, 27, $887-895$ 
34. Trampert S., Gocmez T., Pishinger S., 2008, Thermo-mechanical fatigue life prediction of cylinder head in combustion engines, Journal of Engineering for Gas Turbines and Power, 130, $1-10$

35. Venkateswaran N., Vinobakrishnan R., Balamurugan V., 2011, Thermo-mechanical analysis of the cylinder block with the liner of AFV diesel engine, SAE International Paper, No. 2011-28-0118

36. Xuyang G., Cheng Y., Zhang Z., 2013, Thermo-mechanical fatigue life prediction of heavy duty diesel engine cylinder head, ASME International Mechanical Engineering Congress and Exposition, California

37. Zahedi F., Azadi M., 2012, Low cycle fatigue life analysis of magnesium alloy diesel engine cylinder head, 20th Annual International Conference on Mechanical Engineering, Shiraz

38. Ziehler F., Langmayr F., JelatanceV A., Wieser K., 2005, Thermal mechanical fatigue simulation of cast iron cylinder heads, SAE International Paper, No. 2005-01-0796

Manuscript received April 12, 2015; accepted for print August 4, 2015 